\title{
CHEMOSPHERE
}

Chemosphere 60 (2005) 731-739

www.elsevier.com/locate/chemosphere

\section{A spatial temporal assessment of pollution from PCBs in China}

\author{
Ying Xing ${ }^{\mathrm{a}, \mathrm{b}}$, Yonglong Lu ${ }^{\mathrm{a}, \mathrm{b}, *}$, Richard W. Dawson ${ }^{\mathrm{a}, \mathrm{c}}$, Yajuan Shi ${ }^{\mathrm{a}, \mathrm{b}}$, \\ Hong Zhang ${ }^{\mathrm{a}, \mathrm{b}}$, Tieyu Wang ${ }^{\mathrm{a}, \mathrm{b}}$, Wenbin Liu ${ }^{\mathrm{a}, \mathrm{b}}$, Hongchang Ren ${ }^{\mathrm{a}, \mathrm{b}}$ \\ ${ }^{a}$ Research Center for Eco-Environmental Sciences, Chinese Academy of Sciences, Beijing 100085, China \\ ${ }^{\mathrm{b}}$ Graduate School of the Chinese Academy of Sciences, Beijing 100039, China \\ c Center for Land Study, China Agricultural University, Beijing 100083, China
}

\begin{abstract}
This research represents an assessment of the current state of pollution from polychlorinated biphenyls (PCBs) in China. Various environmental media including sediment, water, organism and soil were analyzed and the spatial character of PCB pollution in each environmental medium was determined. On a national basis, PCB levels in all environmental media were relatively low, with little evidence of major contamination in China's main regions and rivers. However, there were some locations with high PCB concentrations. Sediments in Pearl River $(83.1 \mathrm{ng} / \mathrm{g})$ and its estuary $(58.9 \mathrm{ng} / \mathrm{g})$, Dalian Bay $(58.1 \mathrm{ng} / \mathrm{g})$ and Songhua River $(36.8 \mathrm{ng} / \mathrm{g})$ had relatively high level of PCBs. There were also some areas, which were mainly the industrial pollution sites or PCB equipment storage locations, remained seriously polluted with the highest PCB residue level of $150000 \mathrm{ng} / \mathrm{g}$. In addition, Minjiang Estuary $(985.2 \mathrm{ng} / \mathrm{g})$ and Taihu Lake $(631 \mathrm{ng} / \mathrm{g})$ had high levels of water pollution, while Pearl Estuary $(635.7 \mathrm{ng} / \mathrm{g})$ and Jiaozhou Bay $(273.3 \mathrm{ng} / \mathrm{g})$ had relatively high PCB levels in organisms. PCB pollution in soil was limited to a few special pollution areas with the highest PCB level of $4.5448 \times 10^{6} \mathrm{ng} / \mathrm{g}$. Point source pollution was the common pattern of contamination, influenced primarily by local geographic, economic and historical factors. Analysis of PCB concentrations from the 1980s to 1990s shows an increasing trend, possibly due to the improper disposal of and leakage from PCB containers, chemical transfers, and the general rise of industrial pollution.
\end{abstract}

(c) 2005 Elsevier Ltd. All rights reserved.

Keywords: Persistent organic pollutants (POPs); Environmental media; Distribution; Pollution; China

\section{Introduction}

Polychlorinated biphenyls (PCBs), as persistent organic pollutants (POPs), have been extensively studied during the last 30 years in view of their extensive pro-

\footnotetext{
* Corresponding author. Address: Research Center for EcoEnvironmental Sciences, Chinese Academy of Sciences, Beijing 100085, China. Tel.: +8610 62849118; fax: +861062918177.

E-mail address: score@mail.rcees.ac.cn (Y. Lu).
}

duction and usage, their long-range transport capability within the environment, and their bioaccumulation, persistence, and impact on both ecosystems and human health. Because of increasing concern for the risks posed by their use, they were listed along with eleven other compounds as serious threats to health and the environment by the Stockholm Convention (May 22, 2001).

Prior to 1974, PCBs generally entered the air, soil, water and sediment during their manufacture and use (Wong and Poon, 2003). In China, approximately 
10000 tons of PCBs were produced from 1965 to 1974 (production of PCBs was banned in 1974), with 9000 tons as trichlorobiphenyl and 1000 tons as pentachlorobiphenyl. Trichlorobiphenyl was used primarily in power capacitors applied in electricity production, distribution and transmission, while pentachlorobiphenyl was used mainly as a paint additive (China SEPA, 2003). Following the ban on the production and use of PCBs, most of the outdated PCB-containing equipment (equipment filled with PCBs as dielectric fluid) was removed from use and stored. Unfortunately, some of that equipment has recently been found leaking into the surrounding environment and as such, continues to pose a threat to health and the environment. Other sources of selective PCB pollution stem from the illegal dismantling and/or disposal of PCB-containing equipment, the unwanted by-products from the combustion of chlorine-containing waste through unprotected incineration systems and certain other chemical processes involving organochlorines.

While implementation of PCB controls became an important task in China following ratification of the Stockholm Convention, there was only limited information at the national level regarding the current status of PCB pollution and emission sources. The number of studies about PCBs in China has increased recently in light of a series of global initiatives on POPs and an increasing concern about the risks POPs pose to human health and the environment. Among this growing body of existing research, several have focused on monitoring PCBs within the environment. For instance, Chen et al. (1999), Wu et al. (1999) and Yuan et al. (2001b) investigated PCB levels in sediments from Chinese river/estuary systems, and $\mathrm{PCB}$ contaminations in various water organisms such as mussels was surveyed by Monirith et al. (2003) and Fung et al. (2004). While these studies have advanced our understanding of the nature of the problem posed by PCBs, a significant gap still exists in our knowledge of the extent and spatial character of the PCB situation in China. This study aims to assess the temporal and spatial distributions of PCB levels presented in existing data as a preliminary assessment of the extent and distribution of PCBs in China.

\section{Assessment of PCB pollution in the environment}

Most of the research about environmental contamination from PCBs in China has focused on the eastern part of the country, especially estuarial areas such as those of the Pearl and Yangtze rivers, Bohai Bay on the east coast in north China, and along other major rivers such as Minjiang, Jiulongjiang, Yangtze, and Songhua. The spatial distribution of sampling sites in China along with the relevant quantities (percentages) of PCBs deployed in the different areas is shown in Figs. 1 and 2 (China SEPA, 2003). 45.2\% of all PCBs used in China were used in the east, with an average gross application

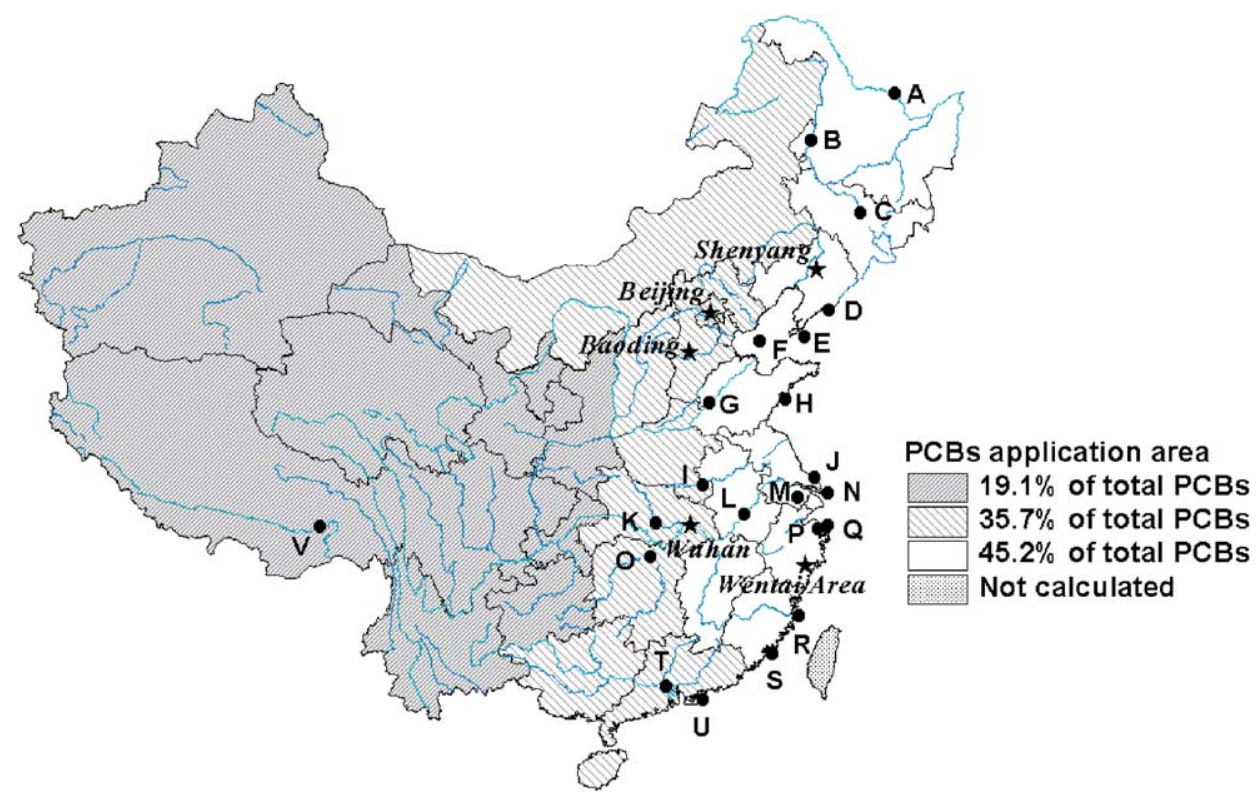

Fig. 1. Sampling locations of PCBs in sediment, organism and water in China. A: Heilongjiang River; B: Nenjiang River; C: Songhua River; D: Yalujiang Estuary; E: Dalian Bay; F: Bohai Sea; G: Yellow River; H: Jiaozhou Bay; I: Huaihe River; J: Lusi Coast; K: Hanshui River; L: Yangtze River; M: Taihu Lake; N: Yangtze Estuary; O: Dongting Lake; P: Ningbo Coast; Q: Zhoushan Coast; R: Minjiang River; S: Jiulongjiang River; T: Pearl River; U: Daya Bay; V: Najiabawa Peak, Tibet. 


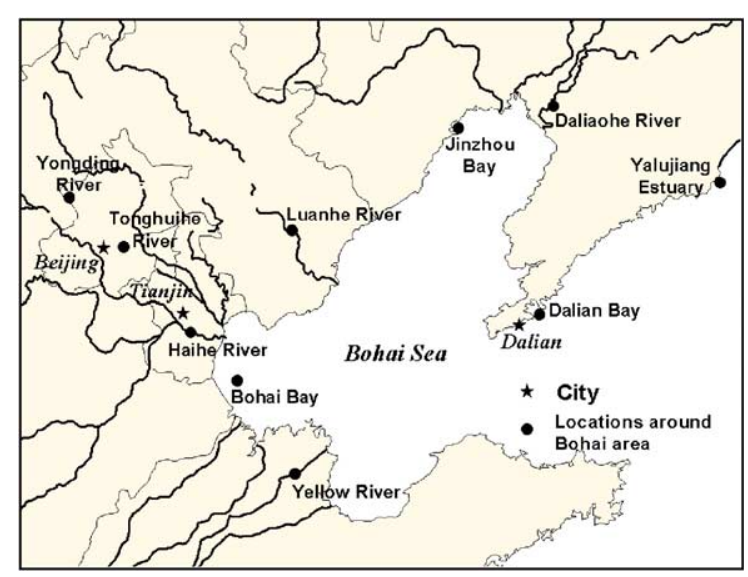

Fig. 2. Sampling locations of PCBs in sediment, organism and water around the Bohai Sea area.

density of $2.86 \mathrm{~kg} / \mathrm{km}^{2}$. After that, $35.7 \%$ were used in the middle section of the country with an average gross application density of $1.29 \mathrm{~kg} / \mathrm{km}^{2}$, while $19.1 \%$ were used in west China with an average gross density of $0.36 \mathrm{~kg} / \mathrm{km}^{2}$. This is not surprising since the vast majority of China's industrial development has occurred in the east and east central portions of the country, especially along major rivers and coastal areas where industrial concentration is highest and manufactured goods could be easily shipped to their final destination.

\subsection{PCBs in sediments}

Average PCB concentrations in sediments collected from the literature are presented in Fig. 3. If different workers investigated the same area, the average level was selected or calculated for presentation in Fig. 3.

Because there is not an environmental standard for the concentration of PCBs in sediments in China, we used a criterion presented by Long et al. (1995) for appraisal purposes. Long et al. (1995) developed two guidelines for use as comparative values, an effects range-low (ERL) standard and an effects range-median (ERM) standard, for assessing a number of trace metals and organic compounds including PCBs in the environment. The ERL and ERM values were intended to define chemical concentration ranges that are rarely, occasionally, or frequently associated with adverse biological effects including altered benthic communities (depressed species richness or total abundance), histopathological disorders in demersal fish, $\mathrm{EC}_{50}$ or $\mathrm{LC}_{50}$ concentrations and toxicity predicted by models. The ERL and ERM guideline values for PCBs adopted here were set at $22.7 \mathrm{ng} / \mathrm{g}$ and $180 \mathrm{ng} / \mathrm{g}$, respectively.

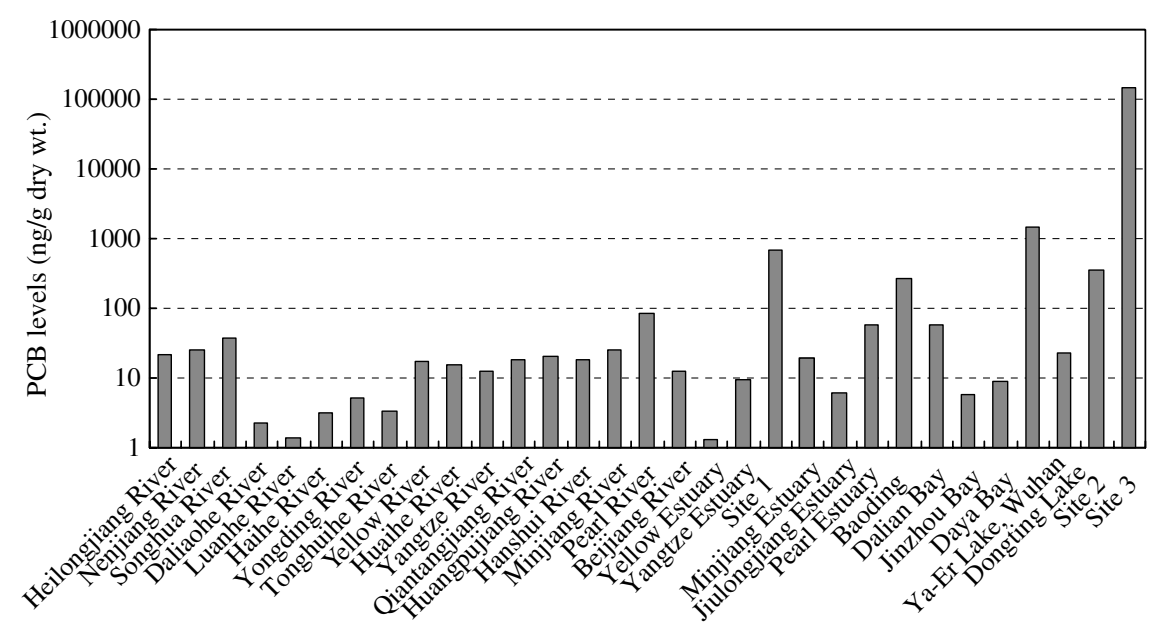

Fig. 3. Average PCB levels in sediments at various sites in China (ng/g dry wt.). Heilongjiang River (Chen et al., 1999), Nenjiang River (Chen et al., 1999), Songhua River (Li et al., 1989; Liu et al., 1998; Chen et al., 1999), Daliaohe River (Wu et al., 1999), Luanhe River (Wu et al., 1999), Haihe River (Wu et al., 1999), Yongding River (Ma et al., 2001), Tonghuihe River (Zhang et al., 2004), Yellow River (Chen et al., 1999), Huaihe River (Chen et al., 1999; Wang et al., 2001), Yangtze River (Chen et al., 1999; Jiang et al., 2000), Qiantangjiang River (Chen et al., 1999; Wu et al., 1999), Huangpujiang River (Wu et al., 1999), Hanshui River (Chen et al., 1999), Minjiang River (Chen et al., 1999), Pearl River (Chen et al., 1999; Kang et al., 2000; Nie et al., 2001; Mai et al., 2002), Beijiang River (Chen et al., 1999), Yellow Estuary (Wu et al., 1999), Yangtze Estuary (Wu et al., 1999; Yang et al., 2002; Chen et al., 2003; Liu et al., 2003; Yang et al., 2003), Site 1 (Chu et al., 1995b), Minjiang Estuary (Yuan et al., 2001a; Zhang et al., 2002, 2003), Jiulongjiang Estuary (Hong et al., 1995; Chen et al., 1996; Wu et al., 1999; Zhou et al., 2000; Yuan et al., 2001a,b), Pearl River Estuary (Hong et al., 1995,1999; Kang et al., 2000; Yuan et al., 2001b), Baoding (China SEPA, 2003), Dalian Bay (Li et al., 1998; Liu et al., 2001), Jinzhou Bay (Li et al., 1998), Daya Bay (Zhou et al., 2001), Ya-Er Lake (Wu et al., 1997), Dongting Lake (Chen et al., 1999), Site 2 (China SEPA, 2003), Site 3 (China SEPA, 2003). 
Among the 31 sites identified in Fig. 3, there were some heavily polluted areas. Site 1 (a PCB pollution area on the southeast coast), an industrial drainage canal used by paper mills in Baoding, Ya-Er Lake near Wuhan which had been polluted by industrial emission 20 years before, Site 2 (a river near a PCB equipment storage location) and Site 3 (another river passing adjacent to a PCB equipment storage facility) had constituents frequently posing biological impairment with concentrations much greater than ERM. Six sites (Nenjiang and Songhua rivers in northeast China, Dalian Bay, and Minjiang River, Pearl River and Pearl Estuary in south China) posed possible adverse biological effects, with average concentrations $(25 \mathrm{ng} / \mathrm{g}, 36.8 \mathrm{ng} / \mathrm{g}$, $58.1 \mathrm{ng} / \mathrm{g}, 25 \mathrm{ng} / \mathrm{g}, 83.1 \mathrm{ng} / \mathrm{g}$, and $58.9 \mathrm{ng} / \mathrm{g}$ ) greater than the ERL limits recommended by Long et al. (1995). Although these locations are important industrial and agricultural areas, none of the samples suggested a serious biological threat, with PCB concentrations less than the ERM standard. Samples taken from Heilongjiang River (northeast China), Yellow and Huaihe rivers, Minjiang Estuary, and some branches of Yangtze River (Qiangtangjiang, Huangpujiang, Hanshui rivers and Dongting Lake) in middle China had average PCB concentrations near the ERL level, suggesting that necessary concern should be given to these locations. Other areas such as the Luanhe, Yongding and Tonghuihe rivers near Beijing, the Daliaohe and Haihe rivers and Jinzhou Bay near Bohai Sea and Yellow River Estuary had relatively low levels of contamination.

Regionally, the distribution of PCB pollution tends to be related to drainage area, industrial patterns, and pollution emissions during the two decades since their production and use was banned. PCB sampling locations and concentrations in sediments along Pearl River are presented in Figs. 4 and 5. PCB levels from Fangcun (485.45 ng/g) to Huangpu at Guangzhou City were probably higher than those in the rural sector (Shiziyang River and Lingding Bay) because of greater levels of industrial emission and municipal sewage as potential sources. Concentrations in sediments in old industrial parks (Zhichang, Yuancun and Huangpu of Guangzhou sector) were also higher than those at the new industrial park or in adjacent residential areas. Along the Guangzhou branch of the Pearl and Shiziyang rivers and Lingding Bay, PCB contamination decreased as the distance to the source increased. Pollution in the estuary was very low $(1.58 \mathrm{ng} / \mathrm{g})$ possibly owing to the influx of large amounts of water from other branches of the river in this area. Also heavily polluted were harbor areas such as Macao and Victoria Harbor 3, as the result of both industrial sources (e.g., a landfill near the Macao's inner Harbor) and hydrological conditions (e.g., a typhoon shelter at Victoria Harbor 3). Fu et al. (2003) also reported that there were two different $\mathrm{PCB}$ pollution sources in the Pearl River/Estuary according to the

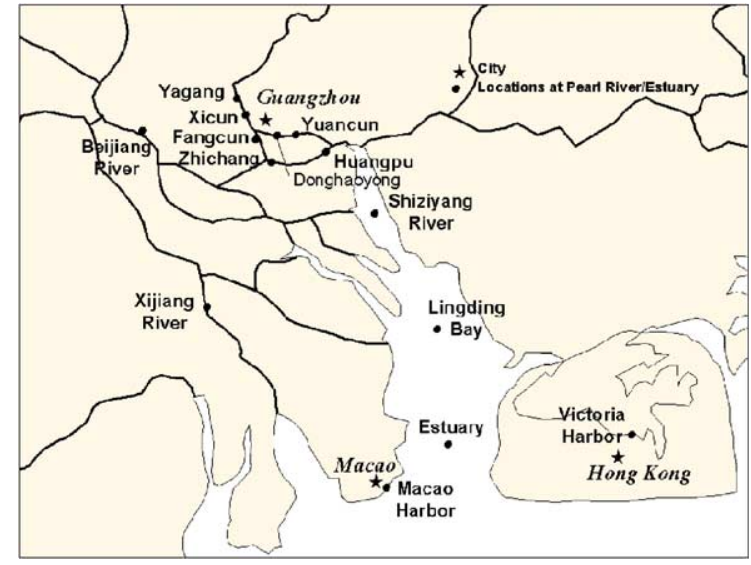

Fig. 4. Sampling locations of PCBs in sediments in Pearl River Estuary.

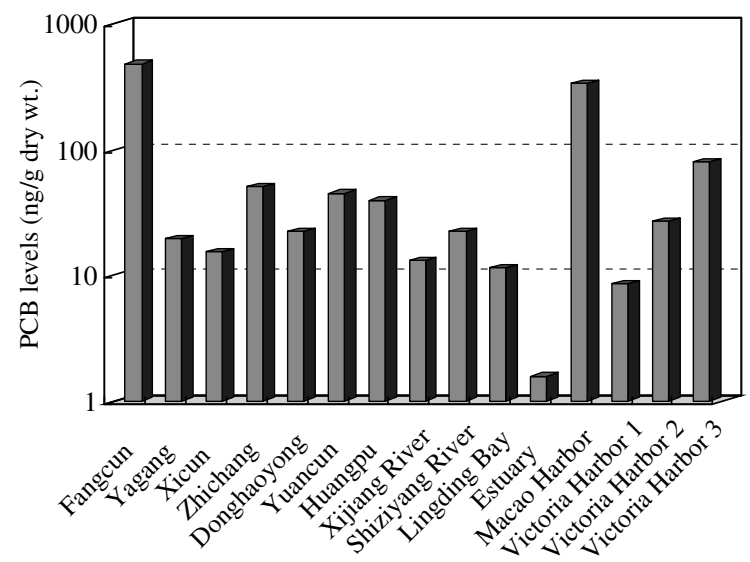

Fig. 5. Average PCB levels in sediments in Pearl River/Estuary (ng/g dry wt.). Fangcun, Xijiang River, Shiziyang River, Lingding Bay, Macao Harbor (Kang et al., 2000); Yagang, Xicun, Zhichang, Donghaoyong, Yuancun, Huangpu (Nie et al., 2001); Estuary (Hong et al., 1999; Yuan et al., 2001b); Viotoria Harbor 1, 2, 3 (Hong et al., 1995).

PCB distribution profile, one from Guangzhou and another from Hong Kong. PCB pollution in the Pearl River Delta sediments seemed to be the result of trace discharges into storm waters, sewage, industrial waste, agricultural runoff, and some atmosphere deposition.

\section{2. $P C B$ pollution in water}

The available surveys about PCBs in water were very deficient and the limited data on PCB concentrations are given in Table 1. According to the USEPA guidelines, the concentration of PCBs should be less than $14 \mathrm{ng} / \mathrm{l}$ 
Table 1

Concentrations of PCBs in water from various sites in China (ng/l)

\begin{tabular}{llcl}
\hline Location & Concentration range & Average concentration & Reference \\
\hline Songhua River & $0.003-0.088$ & 0.013 & Li et al. (1989) \\
Tonghui River & $31.58-344.9$ & 105.5 & Zhang et al. (2004) \\
Jiaozhou Bay & $9.01-12.63$ & 10.82 & Chu et al. (1995a) \\
Huaihe River & $0.24-0.28$ & 0.26 & Wang et al. (1999) \\
Yangtze River & $0.29-2.00$ & 1.24 & Chen et al. (1996); Sun et al. (2002) \\
Taihu Lake & & 631 & Wang et al. (2003) \\
Minjiang Estuary & $203.9-2473$ & 985.2 & Zhang et al. (2003) \\
Jiulongjiang Estuary & $0.1-1505$ & 177.9 & Zhang et al. (2000); Zhou et al. (2000) \\
Pearl Estuary & $1.13-3.11$ & 2.3 & Nie et al. (2002) \\
Daya Bay & $91.1-1355.3$ & 313.6 & Zhou et al. (2001) \\
Dong Lake, Wuhan & & 2.7 & Xi et al. (1998) \\
Nanjiabawa Peak, Tibet & & 0.0093 & Sun et al. (1986) \\
\hline
\end{tabular}

for surface water to be considered no hazard to aquatic or human health (USEPA, 2002). Table 1 identifies those locations with low-levels of PCBs in water. At Nanjiabawa Peak in Tibet, for example, where there are no industrial emissions, the concentration level was only $0.0093 \mathrm{ng} / \mathrm{g}$. Although the contamination level was extremely low in this area, the trace amounts present suggest the possibility that atmospheric transfer may be a working pathway for PCBs to enter the area (Sun et al., 1986). High upper limit concentrations of PCBs were found in the Minjiang and Jiulongjiang estuaries (2473 ng/g and $1505 \mathrm{ng} / \mathrm{g}$, respectively), Daya Bay
(1355.3 ng/g) and Tonghui River (344.9 ng/g). Taihu Lake, an important industrial and agricultural area in middle China, also had a high PCB average level at $631 \mathrm{ng} / \mathrm{l}$ (Fig. 1 and Table 1).

\subsection{PCB pollution in organisms}

PCB concentrations in organism are presented in Table 2. For the levels of same areas investigated by different workers, the average levels were calculated and then listed. Some dry weight values were multiplied by 10 and presented as wet weight according to an

Table 2

Concentrations of PCBs in organisms from various sites in China (ng/g wet wt.)

\begin{tabular}{lccl}
\hline Location & Concentration range & Average concentration & Reference \\
\hline Yalujiang Estuary & & 3.8 & Liu et al. (1996) \\
Daliaohe Estuary & & 0.4 & Liu et al. (1996) \\
Bohai Bay & & 5.4 & Liu et al. (1996) \\
Jinzhou Bay & $4.6-120$ & 1.4 & Liu et al. (1996) \\
Dalian Bay & & & Liu et al. (1996) \\
& & Yu et al. (2002) \\
Jiaozhou Bay & $6.6-540$ & 273.3 & Fung et al. (2004) \\
& & & Liu et al. (1996) \\
Lusi Coast & & 3.2 & Fung et al. (2004) \\
Yangtze Estuary & & 60.69 & Liu et al. (1996) \\
Zhoushan Coast & 47.65 & Fung et al. (2004) \\
Ningbo Coast & 41.13 & Fung et al. (2004) \\
Minjiang Estuary & 30.6 & Fung et al. (2004) \\
& & Chen et al. (2001) \\
Jiulongjiang Estuary & $2.82-69$ & 120.7 & Fung et al. (2004) \\
Pearl Estuary & $37.1-270$ & 635.7 & Chen et al. (2001) \\
& & & Fung et al. (2004) \\
Pearl River & $25-2480$ & 181.9 & Fang et al. (2001) \\
Songhua River & & 61.3 & Monirith et al. (2003) \\
Huaihe River & & 5.96 & Sun et al. (2003)
\end{tabular}

\footnotetext{
a The samples in those locations were fish, while samples in other locations were mussels.
} 
experiential relationship suggested by Sun et al. (2003). The Environmental Chemical Contaminants Control Guidance set up by the United States Food and Drug Administration (USFDA) provided a federal tolerance of PCBs (2000 ng/g wet wt.), which was used as a criterion to assess the PCB contamination status in organisms including fish and fisheries products such as fresh or saltwater finfish, crustaceans, other forms of aquatic animal life and all mollusks (USFDA, 2001).

Most areas had relatively low concentrations (less than USFDA standard of $2000 \mathrm{ng} / \mathrm{g}$ ) of PCBs in mussels or fish. Areas in the north (Yalujiang Estuary and some locations around the Bohai Sea namely Daliaohe Estuary, Bohai Bay, Jinzhou Bay, and Dalian Bay) were slightly less contaminated than the sites in the south, especially the Jiulongjiang and Pearl estuaries and Jiaozhou Bay where industrial and wastewater throughput is relatively large.

Based on evidence collected from crustacean tissue samples, some areas along the southeast coast had higher levels $(691 \mathrm{ng} / \mathrm{g})$ than found just 2 years prior $(22.6 \mathrm{ng} / \mathrm{g})$ or at a nearby island $(0.88 \mathrm{ng} / \mathrm{g}$, Chu et al., $1995 \mathrm{a})$, indicating that PCB contamination from point sources remains an issue in the region.

\subsection{PCB pollution in soil}

Few of the studies surveyed PCB contamination in the soil, and when undertaken, the focus was on already heavily polluted areas. In China, most of the PCB-containing equipment was stored at special sites when they were taken out of use. Because of poor management and storage conditions, however, PCBs from some of these special storage locations have leaked into the surrounding media especially the soil. China SEPA (2003) reported that directly polluted soils in some sealed storage locations reached as high as $4.5448 \times 10^{6} \mathrm{ng} / \mathrm{g}$, with levels in surrounding lands and farmlands having as much as $2930 \mathrm{ng} / \mathrm{g}$.

Along China's southeast coast where some residents were illegally trading in or dismantling PCB-containing equipment, $\mathrm{PCB}$ concentrations have been found as high as $788 \mathrm{ng} / \mathrm{g}$ dry wt. (Chu et al., 1995b). In the Wentai Area, for example, the arbitrary disposal of used electric appliances resulted in a major PCB pollution accident in 1989, with PCB levels reaching $1101.4 \mathrm{ng} / \mathrm{g}$ in an adjacent rice field in 1993. Following the ban on such activity, pollution levels decreased to $568.15-920.08 \mathrm{ng} / \mathrm{g}$ in 1997 and by 1999 were down to $2.01-7.34 \mathrm{ng} / \mathrm{g}$ (Bi et al., 2002).

Agricultural soils sampled in suburban Beijing reported concentration levels of only $0.18 \mathrm{ng} / \mathrm{g}$ (Chu et al., 1995b) and soils sampled from Shenyang, a major industrial city in north China's Liaoning Province, had PCB levels of 6.4-15.2 ng/g (Jing et al., 1992). Compared to the allowable level of $60 \mathrm{ng} / \mathrm{g}$ for PCBs in ambient soil approved by the former Union of Soviet Socialist Republics (USSR) Ministry of Health in 1991, both areas had relatively slight PCB contamination levels on average (Bobovnikova et al., 1993; Bi et al., 2002). While the broad average pollution situation seems to be in control, the threat posed by seriously polluted point sources remains real and should not be overlooked in assessing the risks identified by current data.

\section{Temporal PCB pollution in China}

Monitoring of PCBs in the environment has not been extensive, with inadequate funding and little policy support adding to the difficulties in China. In addition, few of the places were investigated more than once. Data collected over time for some of the main rivers and estuaries are presented in Fig. 6. The results indicate that concentrations of PCBs in most areas of China increased during the 1980s and 1990s, with the exception of Yangtze River and Dalian Bay. This variation in environmental PCB levels is in contrast to results presented in most foreign studies where concentrations of PCBs have been decreasing since the 1970s (Giesy and Snyder, 1998; Muir and Norstrom, 2000; Marvin et al., 2004).

There are two possible reasons behind this difference. In China, the production of PCB capacitors was greatest between 1965 and 1974 and China also imported large quantities of PCB transformers in the 1970s and 1980s accompanied by other large size/scale purchases of integrated mechanical and electrical equipment (China SEPA, 2003). If the calculated service life of 15-20 years for such equipment is taken into consideration, they would be scheduled for removal from service during

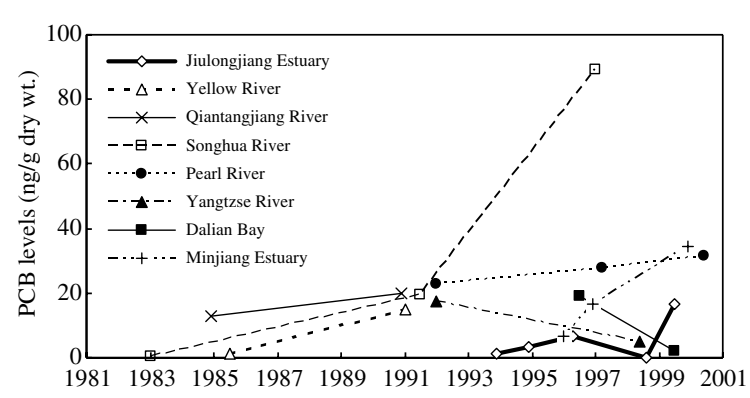

Fig. 6. Temporal trend of PCB levels in sediments in some main rivers of China. Jiulongjiang Estuary (Hong et al., 1995; Chen et al., 1996; Wu et al., 1999; Yuan et al., 2001b), Minjiang Estuary (Yuan et al., 2001a,b; Zhang et al., 2002, 2003), Yellow River (Chen et al., 1999; Wu et al., 1999), Qiantangjiang River (Chen et al., 1999; Wu et al., 1999), Songhua River (Li et al., 1989; Liu et al., 1998; Chen et al., 1999), Pearl River (Chen et al., 1999; Kang et al., 2000; Nie et al., 2001), Yangtze River (Chen et al., 1999; Jiang et al., 2000) and Dalian Bay (Li et al., 1998; Liu et al., 2001). 
the 1980s and 1990s. Further, because of excessive lags in management, lack of knowledge about the negative effects of PCBs, and poorly developed institutional support, most of the PCB-containing equipment was disposed improperly such as through uncontrolled combustion or storage under bad conditions, which caused the gradual emission of PCBs into environment in 1980-1990s. In addition, the Chinese economy was developing rapidly during this same period, and dramatic increases in pollution emissions accompanied the booming economy. As a by-product, PCBs could have entered the surrounding environment through multiple pathways. Given the trend observed during the 1980s and 1990s, it is likely that some areas in China will continue to experience increases in PCB levels in the future if controlling measures are not carried out.

\section{Conclusion}

Based on very general environmental criteria PCB concentrations in environmental media in China were relatively low on a national scale. That may be partly because PCBs were not produced in China with any great abundance relatively speaking, and they were used for a relatively short time. Based on existing information, there was little contrast in PCB contamination among the main regions, rivers, and estuaries investigated. On a regional scale, however, there were some significantly polluted areas and historic use sites causing serious local pollution with possible long-term affects. PCB residues in the sediments of some rivers and estuaries in China's northeast and southern regions were more seriously polluted (Pearl River/Estuary system, Songhua River, Ya-Er Lake and Dalian Bay) than other areas. Waters in the Minjiang Estuary and Taihu Lake in southeast China were extremely polluted, and Jiaozhou Bay and Pearl Estuarie had relatively high PCB level in organisms. Soils polluted by PCBs were found near special point sources reflecting problems associated with the improper dismantling and storage of old PCB-containing equipment. Local geographic, economic and historical factors also had a noticeable effect on the incidence and diffusion of pollution resulting from PCBs. In addition to the rise of pollution emissions from rapid economic development, PCB concentrations in most areas of China increased during the 1980s and 1990s due to improper disposal as well as leakage from PCB-containing equipment.

\section{Acknowledgement}

This research was supported by the Knowledge Innovation Program of the Chinese Academy of Sciences with Grant No. KZCX2-414.

\section{References}

Bi, X.H., Chu, S.G., Meng, Q.Y., Xu, X.B., 2002. Movement and retention of polychlorinated biphenyls in a paddy field of WenTai area in China. Agriculture, Ecosystems and Environment 89, 241-252.

Bobovnikova, T., Dibtseva, A., Mitroshkov, A., Pleskachevskaya, G., 1993. Ecological assessment of a region with PCB emissions using samples of soil, vegetation and breast milk: a case study. The Science of the Total Environment 139/140, 357-364.

Chen, J.S., Gao, X.M., Qi, M., Jessica, B., 1999. The contents of polychlorinated biphenyl in river sediments in eastern China. Acta Scientiae Circumstantiae 19 (6), 614-618 (in Chinese).

Chen, M.R., Yu, L.Z., Xu, S.Y., Feng, K., Han, X.F., 2003. Spatial distribution of PCBs in the sediments of Changjiang Estuary tidal-flat. Marine Environmental Science 22 (2), 20 23 (in Chinese).

Chen, W.Q., Zhang, L.P., Wang, X.H., Hong, L.Y., Hong, H.S., 2001. Residue levels of persistent organochlorine pesticides and polychlorinated biphenyls in shellfish samples from eastern Xiamen Island and Minjiang Estuary. Journal of oceanography in Taiwan Strait 20 (3), 329-334 (in Chinese).

Chen, W.Q., Zhang, L.P., Xu, L., Wang, X.H., Hong, H.S., 1996. Vertical distribution characteristics of organochlorinated pesticides and polychlorinated biphenyls in sediments of Xiamen Bay. Marine Science 2, 56-60 (in Chinese).

China SEPA, 2003. Building the capacity of the People's Republic of China to implement the Stockholm convention on POPs and develop a National implementation plan. GEF Project Brief (GF/CPR/02/010).

Chu, S.G., Xu, X.B., Tong, Y.P., 1995a. Transport and distribution of polychlorinated biphenyls in a polluted area. Acta Scientiae Circumstantiae 15 (4), 423-432 (in Chinese).

Chu, S.G., Yang, C., Xu, X.B., Liu, X.X., 1995b. Polychlorinated biphenyl congener residues in sediment and soil from pollution area. China Environmental Science 15 (3), 199203 (in Chinese).

Fang, Z.Q., Cheung, R.Y.H., Wong, M.H., 2001. Concentrations and distribution of organochlorinated pesticides and PCBs in green-lipped mussels, Perna viridis collected from the Pearl River Estuarine Zone. Acta Scientiae Circumstantiae 21 (1), 113-116 (in Chinese).

Fu, J.M., Mai, B.X., Sheng, G.Y., Zhang, G., Wang, X.M., Peng, P.A., Xiao, X.M., Ran, R., Cheng, F.Z., Peng, X.Z., Wang, Z.S., Tang, W., 2003. Persistent organic pollutants in environment of the Pearl River Delta, China: an overview. Chemosphere 52, 1411-1422.

Fung, C.N., Lam, J.C.W., Zheng, G.J., Connell, D.W., Monirith, I., Tanabe, S., Richardson, B.J., Lam, P.K.S., 2004. Mussel-based monitoring of trace metal and organic contaminants along the east coast of China using Perna viridis and Mytilus edulis. Environmental Pollution 127, 203-216.

Giesy, J.P., Snyder, E.M., 1998. Xenobiotic modulation of endocrine function in fishes. In: Kendall, R.L., Dickerson, J.P., Giesy, J.P., Suk, W.P. (Eds.), Principles and Processes for Evaluating Endocrine Disruptors in Wildlife. SETAC Press, Pensacola, FL, pp. 155-237. 
Hong, H., Xu, L., Zhang, L., Chen, J.C., Wong, Y.S., Wan, T.S.M., 1995. Environmental fate and chemistry of organic pollutants in the sediment of Xiamen and Victoria Harbours. Marine Pollution Bulletin 31, 229-236.

Hong, H.S., Chen, W.Q., Xu, L., Wang, X.H., Zhang, L.P., 1999. Distribution and fate of organochlorine pollutants in the Pearl River Estuary. Marine Pollution Bulletin 39, 376382.

Jiang, X., Xu, S.F., Martens, D., Wang, L.S., 2000. Polychlorinated organic contaminants in waters, suspended solids and sediments of the Nangjing section, Yangtze River. China Environmental Science 20 (3), 193-197 (in Chinese).

Jing, Z.Y., Li, Y.H., Feng, X.B., Wang, F.Q., Zhang, Y.X., 1992. The study of polychlorinated biphenyls for their loss, contamination and protection strategy in Shenyang City. Congkan of Environmental Science 13 (5), 1-28 (in Chinese).

Kang, Y.H., Sheng, G.Y., Fu, J.M., Mai, B.X., Lin, Z., Zhang, G., Min, Y.S., 2000. Preliminary study on the distribution and characterization of polychlorinated biphenyls in some of surface sediments from Pearl River Delta. Environmental Chemistry 19 (3), 262-269 (in Chinese).

Li, H., Fu, Y.Z., Zhou, C.G., Xu, H.Z., 1998. Distribution characteristics of organic chlorine pesticide and PCB in the surface sediments in Dalian Bay and Jinzhou Bay. Marine Environmental Science 17 (2), 73-76 (in Chinese).

Li, M.X., Yue, G.C., Gao, F.M., Du, Y.G., 1989. Transport and distribution of PCBs and organochlorine pesticides in the second Songhua River. Environmental Chemistry 8 (2), 49-54 (in Chinese).

Liu, J.A., Wang, W.H., Wang, Z.J., 1998. Sorts and contents of persistent pollutants in the sediment samples of the second Songhua River. China Environmental Science 18 (6), 518 520 (in Chinese).

Liu, M., Yang, Y., Hou, L., Xu, S., Ou, D., Zhang, B., Liu, Q., 2003. Chlorinated organic contaminants in surface sediments from the Yangtze Estuary and nearby coastal areas, China. Baseline/Marine Pollution Bulletin 46, 659-676.

Liu, R.Y., Wu, S.P., Wang, B., 1996. Distribution and evaluation of the organic chlorine pesticide and PCB in the economic shellfish from north of the Changjiang Mouth. Marine Environmental Science 15 (3), 29-35 (in Chinese).

Liu, X.M., Xu, X.R., Zhang, X.T., Zhang, G.G., Li, H., Zhou, C.G., 2001. Organchlorine pesticides and PCBs in Dalian Bay. Marine Environmental Science 20 (4), 40-44 (in Chinese).

Long, E.R., MacDonald, D.D., Smith, S.L., Calder, F.D., 1995. Incidence of adverse biological effects within ranges of chemical concentrations in marine and estuary sediments. Environmental Management 19, 81-97.

Ma, M., Wang, Z.J., Sodergren A, 2001. Contamination of PCBs and organochlorinated pesticides in the sediment samples of Guanting Reservoir and Yongding River. Environmental Chemistry 20 (3), 238-243 (in Chinese).

Mai, B.X., Fu, J.M., Sheng, G.Y., Kang, Y.H., Lin, Z., Zhang, G., Min, Y.S., Zeng, E.Y., 2002. Chlorinated and polycyclic aromatic hydrocarbons in riverine and estuarine sediments from Pearl River Delta, China. Environmental Pollution 117, 457-474.

Marvin, C.H., Painter, S., Charlton, M.N., Fox, M.E., Lina Thiessen, P.A., 2004. Trends in spatial and temporal levels of persistent organic pollutants in Lake Erie sediments. Chemosphere 54, 33-40.

Monirith, I., Ueno, D., Takahashi, S., Nakata, H., Sudaryanto, A., Subramanian, A., Karuppiah, S., Ismail, A., Muchtar, M., Zheng, J.S., Richardson, B.J., Prudente, M., Hue, N.D., Tana, T.S., Tkalin, A.V., Tanabe, S., 2003. Asia-Paci.c mussel watch: monitoring contamination of persistent organochlorine compounds in coastal waters of Asian countries. Marine Pollution Bulletin 46, 281-300.

Muir, D.C.G., Norstrom, R.J., 2000. Geographical differences and time trends of persistent organic pollutants in the Arctic. Toxicology Letters 112-113, 93-101.

Nie, X.P., Lan, C.Y., Luan, T.G., Huang, M.H., Mai, Z.Q., 2001. Polychlorinated biphenyls in the waters, sediments and benthic organisms from Guangzhou reach of Pearl River. China Environmental Science 21 (5), 417-421 (in Chinese).

Nie, X.P., Lan, C.Y., Luan, T.G., Wei, T.L., Huang, M.H., 2002. Rapid determination of PCBs in seawater of Pearl River Delta by solid-phase microextraction. Marine Environmental Science 21 (2), 65-68 (in Chinese).

Sun, C., Dong, Y., Xu, S., Yao, S., Dai, J., Han, S., Wang, L., 2002. Trace analysis of dissolved polychlorinated organic compounds in the water of the Yangtse River (Nanjing, China). Environmental Pollution 117, 9-14.

Sun, C., Xu, S.F., Yao, S.C., Wang, L.S., Chiu, S.T., Ye, D.Y., Chau, O., 2003. Study on PCBs in the green mussel (Perna viridis L.) samples in Hong Kong marine water. Environmental Chemistry 22 (2), 182-188 (in Chinese).

Sun, W.X., Chen, R.L., Sun, A.Q., Zhang, H.X., Liu, Q.Y., Shi, G.H., 1986. Pollution of organochlorinated compounds at Nanjiabawa Peak area. Environmental Science 7 (6), 64 69 (in Chinese).

USEPA (United States Environmental Protection Agency), 2002. National Recommended Water Quality Criteria: EPA-822-R-02-047. Available from: <http://www.epa.gov/ ost/pc/revcom.pdf>.

USFDA (United States Food and Drug Administration), 2001. Fish and fisheries products hazards and controls guidance. CHAPTER 9, Environmental Chemical Contaminants and Pesticides. Available from: <http://www.cfsan.fda.gov/ $\sim$ comm/haccp4i.html $>$.

Wang, H., Wang, C.X., Wu, W.Z., Mo, Z., Wang, Z.J., 2003. Persistent organic pollutants in water and surface sediments of Taihu Lake, China and risk assessment. Chemosphere 50, $557-562$.

Wang, Y., Wang, Z.J., Liu, J.A., Ma, M., Wang, C.X., 1999. Monitoring toxic and organic pollutants in the Huaihe River using Triolein-SPMD. Environmental Monitoring in China 15 (4), 8-11 (in Chinese).

Wang, Z.J., Wang, Y., Ma, M., 2001. Assessing the ecological risk of sediment-associated polychlorinated biphenyls in Huaihe River. China Environmental Science 21 (3), 262-265 (in Chinese).

Wong, M.H., Poon, B.H.T., 2003. Sources, fates and effects of persistent organic pollutants in China, with emphasis on the Pearl River Delta. In: The Handbook of Environmental Chemistry. In: Fiedler, H. (Ed.), Part O Persistent Organic Pollutants, vol. 3. Springer-Verlag, Berlin Heidelberg, pp. 355-369. 
Wu, W.Z., Schramm, K.W., Henkelmann, B., Xu, Y., Yediler, A., Kettrup, A., 1997. PCDD/Fs, PCBs, HCHs, and HCB in sediments and soils of Ya-Er Lake area in China: results on residual levels and correlation to the organic carbon and the particle size. Chemosphere 34 (1), 191-202.

Wu, Y., Zhang, J., Zhou, Q., 1999. Persistent organochlorine residues in sediments from Chinese river/estuary systems. Environmental Pollution 105, 143-150.

Xi, Z.Q., Chu, S.G., Xu, X.B., Zhang, Y.Y., Xu, Y., 1998. Determination of polychlorinated biphenyls in Donghu Lake. Oceanologia et Limnologia Sinica 29 (4), 436-440 (in Chinese).

Yang, Y., Liu, M., Hou, L.J., 2002. Distribution of polychlorinated organic compound in Yangtze Estuary and its correlation with TOC and particle size. Shanghai Environmental Sciences 21 (9), 530-532 (in Chinese).

Yang, Y., Liu, M., Xu, S.Y., Hou, L.J., Liu, H.L., 2003. Distribution of polychlorinated biphenyls (PCBs) and organochlorine pesticides (OCPs) in the tidal beach surface sediments of Yangtze estuary. China Environmental Science 23 (2), 215-219 (in Chinese).

Yu, Q., Li, Y.M., Zhang, H., Zhong, H.M., Cong, L.Y., Luo, L.M., Wang, K.Q., Xu, X.R., Liu, X.M., 2002. Determination of organochlorine pesticides and polychlorinated biphenyls in mussel and oyster by gas chromatography. Journal of Instrumental Analysis 21 (2), 91-93 (in Chinese).

Yuan, D.X., Yang, D.N., Chen, M., Xu, P.X., Qian, Y.R., Wang, J.L., 2001a. Concentrations and distribution of polycyclic aromatic hydrocarbons and organo-chlorides in surface sediment of Xiamen Western Harbour and Minjiang
Estuary. Acta Scientiae Circumstantiae 21 (1), 107-112 (in Chinese).

Yuan, D.X., Yang, D.N., Wade, T.L., Qian, Y.R., $2001 \mathrm{~b}$. Status of persistent organic pollutants in the sediment from several estuaries in China. Environmental Pollution 114, 101-111.

Zhang, Z.L., Chen, W.Q., Maskaoui, Khalid, Zhou, J.L., Xu, L., Hong, H.S., 2000. Study on PCBs in Water of Jiulong River Estuary. YunNan Environmental Science 19, 124-127 (in Chinese).

Zhang, Z.L., Hong, H.S., Yu, G., 2002. Preliminary study on persistent organic pollutants (POPs) - PCBs in multi-phase matrices in Minjiang River Estuary. Acta Scientiae Circumstantiae 22 (6), 788-791 (in Chinese).

Zhang, Z.L., Hong, H.S., Zhou, J.L., Huang, J., Yu, G., 2003. Fate and assessment of persistent organic pollutants in water and sediment from Minjiang River Estuary, Southeast China. Chemosphere 52, 1423-1430.

Zhang, Z.L., Huang, J., Yu, G., Hong, H.S., 2004. Occurrence of PAHs, PCBs and organochlorine pesticides in the Tonghui River of Beijing, China. Environmental Pollution 130 (2), 249-261.

Zhou, J.L., Hong, H., Zhang, Z., Maskaoui, K., Chen, W., 2000. Multi-phase distribution of organic micropollutants in Xiamen Harbour, China. Water Research 34 (7), 21322150.

Zhou, J.L., Maskaoui, K., Qiu, Y.W., Hong, H.S., Wang, Z.D., 2001. Polychlorinated biphenyl congeners and organochlorine insecticides in the water column and sediments of Daya Bay, China. Environmental Pollution 113, 373-384. 